\title{
Synthesis of Chitosan-Graft- HP $\beta C D$ Copolymer by Novel One Pot Technique and its Application for Solubility Enhancement of Efavirenz
}

\author{
Aarti Belgamwar, Shagufta Khan,* Lalit Rathi \\ Institute of Pharmaceutical Education and Research, Borgaon (Meghe), Wardha-442001, Maharashtra, INDIA
}

\begin{abstract}
Objective: To enhance solubility of efavirenz by using chitosan-graft-HP $\beta C D$ copolymer synthesized by novel one pot technique. Methodology: Poor aqueous solubility and limited bioavailability is the major problem for more than $40 \%$ NEC (new chemical entities). Efavirenz (EFV), widely used non nucleoside reverse transcriptase inhibitor (NNRTI) belongs to BCS class II drug is having very poor intrinsic water solubility and limited oral bioavailability. Chitosan - graft-HPßCD (CS-g-HPßCD) copolymer was synthesized by tosylation of HPßCD followed by grafting on chitosan (CS) backbone. CS-g-HPBCD was prepared by varying CS: HP $\beta C D$ weight ratios $(1: 1,1: 2$, 1:3 and 1:4). The copolymer was characterized by FT-IR, NMR and DSC The molecular weight of grafted copolymer was determined and copolymer was further evaluated for its solubility enhancement capability. Result: Tosylated HP $\beta C D$ was grafted on CS backbone by simple one pot synthesis method. FT-IR, NMR and DSC results avowed the synthesis of grafted copolymer. The molecular weight of grafted polymer was greater than molecular weight of CS also support confirmation of HPBCD grafting on CS. The copolymer was found to tremendously enhance aqueous solubility of EFV (380 times the solubility of drug in water). These results conclusively
\end{abstract}

demonstrated synthesis of grafted copolymer possessing good potential in the solubility enhancement of the poorly water soluble drug like EFV. Conclusion: Grafted copolymer is an excellent strategy to conquer the solubility issues of hydrophobic drugs like EFV owing to solubility enhancement capability and mucoadhesivity.

Key words: Chitosan, Chitosan-g-HP $\beta C D$, Efavirenz, Hydroxypropyl- $\beta$ cyclodextrin, Grafting, Solubility enhancement.

\section{Correspondence :}

Shagufta Khan,

Professor, Department of Pharmaceutics

Institute of Pharmaceutical Education and Research

Borgaon (Meghe) Wardha-442001, Maharashtra, INDIA.

Phone : 91 7152240284, Fax No. 917152241684

Email: shaguftakhan17@ rediffmail.com

DOI: 10.5530/jyp.2017.9.34

\section{INTRODUCTION}

There has been growing interest in studies on graft co-polymerization of polysaccharide chitosan (CS) to introduce novel functions into this biopolymer. CS, a deacetylated derivative from chitin allows specific chemical modifications since it has primary amine group at the $\mathrm{C}-2$ position and primary alcoholic group at the C-6 position of its monomeric units. ${ }^{1-3}$ Graft modification improves CS water solubility and bioactivities such as antibacterial, antioxidant, ${ }^{4,5}$ chelation, ${ }^{6}$ and complexation properties ${ }^{7}$ while maintaining its mucoadhesive and biocompatible properties.

Cyclodextrin (CD) grafted or cross linked with CS are now being developed into 'smart' systems for modifying drug release behavior, solubility and efficient targeted drug delivery especially for hydrophobic drugs. Cyclodextrin consists of ( $\alpha-1,4)$-linked $\alpha$-D-glucopyranose units with lipophillic central cavity and hydrophilic outer surface. The hydroxyl functions are oriented to the cone exterior with the primary hydroxyl groups at narrow edge ( $6^{\text {th }}$ position $)$ and the secondary at the wider edge ( $2^{\text {nd }}$ and $3^{\text {rd }}$ position $)$. Recently, studies on the functionalization or modifications of CDs at the secondary side to alter its properties have gained interest. ${ }^{8}$

To date, various approaches have been proposed to link cyclodextrin to chitosan using different methods of preparation. As reported by Prabaharan and Mano, ${ }^{9}$ tosylated $\beta$-CD was linked to chitosan at the 2 -position of $\mathrm{CD}$. Chen and Wang, ${ }^{10}$ modified iodine release with chitosan- $\beta$-cyclodextrin-iodine complex. $\mathrm{Lu} \mathrm{Lu}$ and co-workers ${ }^{11}$ conjugated $\beta$-CD to $\mathrm{CS}$ through click chemistry to synthesize copolymer chitosan-graft- $\beta$-cyclodextrin. They utilized chitosan-graft- $\beta$-cyclodextrin and carboxymethyl chitosan for formulation of Doxorubicin hydrochloride nanoparticles. Asteria Luzardo-Alvarez ${ }^{12}$ developed hydrophobically modified chitosan containing $\beta$-CD by tosylation which was used to obtain crosslinked microparticles. Poor solubility of CD-g-CS in water was improved by introduction of glycidyltrimethyl ammonium chloride as a quaternizing agent while this novel quaternized CD-g-CS (QCD-g-CS) showed higher antimicrobial activity. ${ }^{13}$ Inclusion complex of QCD-g-CS derivatives when studied with Eugenol expressed excellent mucoadhesion and higher antimicrobial activity. ${ }^{14}$ Present study is focused towards grafting of highly water soluble Hydroxypropyl- $\beta$-cyclodextrin (HP $\beta C D$ ) on CS backbone in order to obtain a copolymer having free water solubility, high yield and having capability to modify CS with hydrophobic cavities of HP $\beta C D$ for better inclusion complex formation with chemical entities having low water solubility while maintaining mucosal adhesivity, permeability and biocompatibility properties of CS.

Efavirenz (EFV), first line non-nucleoside reverse transcriptase inhibitors (NNRTI) is used as a model drug. It belongs to BCS class II category having high lipophilicity $(\log P=5.4)$, poor intrinsic water solubility $(4 \mu \mathrm{g} / \mathrm{ml})$, limited oral bioavailability $(40-50 \%)$, with high intra and inter-individual variability of $19-24 \%$ and $55-58 \%$ respectively. ${ }^{15,16}$ 
In the present study, one-pot synthesis technique was used for grafting of $\mathrm{HP} \beta \mathrm{CD}$ on CS backbone. The grafted copolymer was then studied for solubility enhancement of EFV.

\section{MATERIALS AND METHODS}

\section{Materials}

Chitosan was the generous gift from Mehtani Pvt. Ltd Gujrat, India. Hydroxypropyl- $\beta$-cyclodextrin was supplied by Roquettee India Pvt Ltd, Mumbai, India. Efavirenz was kindly supplied by Aurobindo Pharma Co. Hyderabad, India. All other chemicals used for study were of analytical grade.

\section{Methods \\ Preparation of Chitosan grafted hydroxy propyl- $\beta$-cyclodextrin (CS-g-HPßCD)}

Tosylated HP- $\beta$-CD (Ts- HP $\beta C D$ ) was synthesized with modifications of Brady et al's method. ${ }^{17}$ Briefly, $\mathrm{HP} \beta C D(1 \mathrm{~g}$, mol.wt 1391.221) was dissolved in $2 \mathrm{~mL}$ of distilled water containing $\mathrm{NaOH}(60 \mathrm{mg})$ at freezing temperature. P-toluene sulphonyl chloride (Ts-Cl) $(1 \mathrm{~g})$ was dissolved in Acetonitrile $(3 \mathrm{~mL})$ and added drop-wise to HP- $\beta$-CD solution with constant stirring for $6 \mathrm{hr}$ by strictly maintaining freezing temperature. CS (mol. wt $435 \mathrm{KDa}$ ) was grafted with HP- $\beta-\mathrm{CD}$ according to Gonil's method with modifications. ${ }^{13}$ Ts- HP $\beta C D$ solution was mixed with CS solution in distilled water $(1 \mathrm{~g}$ in $80 \mathrm{~mL})$. Resultant solution was refluxed for $24 \mathrm{~h}$ at $50^{\circ} \mathrm{C}$. It was dialyzed across the dialysis membrane-70 (Molecular weight cut-off 12,000 -14,000 kDa) in deionized water for 4 days. The solution was then freeze dried and cotton like fluffy powder was obtained. CS-g-HP $\beta C D$ was prepared by varying CS: HP $\beta C D$ weight ratios $(1: 1,1: 2,1: 3$ and $1: 4)$.

\section{Characterization of CS- $g-H P \beta C D$}

The grafted copolymer was characterised by FTIR, NMR, DSC and XRD for the confirmation of conjugation between CS and HP $\beta C D$ and molecular weight was also determined.

\section{Fourier transform infrared spectra (FT-IR)}

The Fourier transform infrared (FT-IR) spectra of the of CS, HP $\beta C D$, physical mixture of CS with $\operatorname{HP} \beta C D(1: 1)$, CS-g-HP $\beta C D(1: 1,1: 2,1: 3$ and 1:4), EFV and physical mixture of CS-g-HP $\beta C D$ with EFV were recorded on FTIR spectrophotometer (Shimadzu Asia Pacific Pvt. Ltd. Singapore spectrometer Model No - 84005) in the range of $4000-400 \mathrm{~cm}^{-1}$ using $\mathrm{KBr}$ pellets.

\section{Nuclear magnetic resonance spectroscopy (NMR)}

The ${ }^{1} \mathrm{H}$ NMR spectra of CS and CS-g-HP $\beta C D$ (1:1, 1:2, 1:3 and 1:4) were recorded on NMR (BRUKER BioSpin Group AVANCE II $400 \mathrm{MHz}$ NMR spectrometer, Germany) using tetramethyl silane as an internal standard and $\mathrm{D}_{2} \mathrm{O}$ as a solvent for dissolving at $25^{\circ} \mathrm{C}$.

\section{Differential scanning calorimetry (DSC)}

Differential scanning calorimetric analysis was performed (Mettler Toledo AG, Analytical, Switzerland) to investigate the thermal and crystalline behavior of CS, HP $\beta C D$, physical mixture of CS with HP $\beta C D$ (1:1), CS-g-HP $\beta C D, E F V$ and physical mixture of CS-g-HP $\beta C D$ with EFV (1:1). A heating rate of $10^{\circ} \mathrm{C} / \mathrm{min}$ was employed in the range of $40-450^{\circ} \mathrm{C}$. Analysis was performed under nitrogen purge $(50 \mathrm{~mL} / \mathrm{min})$.

\section{Determination of molecular weight}

Molecular weight of CS-g-HP $\beta C D$ was determined using Zeta sizer ZS90, (Malvern Instrument Ltd., UK) by static light scattering (SLS) process, a technique which characterises the molecules in the solution. Intensity of scattered light that a particle produces is proportional to the product of the weight-average molecular weight and the concentration of the particle. The sample at different concentrations were prepared in a range of 0.25 to $1 \mathrm{~g} / \mathrm{L}$ using distilled water. Toluene was used as standard solvent. Absolute molecular weight was determined using Debey plot.

\section{Solubility determination}

Phase solubility study was carried out according to the Higuchi and Conners method. ${ }^{18}$ An excess amount of drug was added to $10 \mathrm{~mL}$ polymeric solution in distilled water. Solubility was determined with the ratios of CS and $\operatorname{HP} \beta C D(1: 1,1: 2,1: 3,1: 4)$ in CS-g-HP $\beta C D$ in increasing concentrations from $1 \mathrm{mg} / \mathrm{mL}$ to $5 \mathrm{mg} / \mathrm{mL}^{19}$ The series of suspensions were equilibrated by stirring at $25^{\circ} \mathrm{C} \pm 0.5^{\circ} \mathrm{C}$ for $72 \mathrm{hr}$ and then centrifuged. The supernatant was analyzed by double beam UV spectrophotometer (Model No-UV 2401 PC, Shimadzu, Japan) at $246 \mathrm{~nm}$ and amount of drug dissloved was calculated. Same procedure was repeated for pure drug in distilled water. The experiments were performed in triplicate, coefficient of variation associated with each measurement was never $>3 \%$.

\section{RESULTS AND DISCUSSION}

\section{Preparation of Chitosan grafted 2-hydroxy propyl- $\beta$-cyclodextrin (CS-g-HPßCD)}

Tosylation of cyclodextrin is a widely used method for the conjugation of primaryhydroxylgroupsof the Tosylated-Cyclodextrin(Ts-CD) withother functional groups such as amino ofCS. Tosylation is essential for the activation of $-\mathrm{OH}$ group of $\mathrm{HP} \beta \mathrm{CD}$. For grafting of Ts-HP $\beta \mathrm{CD}$ on $\mathrm{CS}$ backbone, a novel one pot synthesis technique was developed. Ts- HP $\beta C D$ is obtained in solubilized form which directly reacted with CS under acidic environment at $50^{\circ} \mathrm{C}$ minimizing the reaction steps and time. The method resulted in the high yield of the copolymer $(17 \pm 2.64 \%)$ and the copolymer had high water solubility.

One pot synthesis technique developed in the present study is simple, scalable and reproducible as compared to the previously reported methods such as method developed by Brady et al. ${ }^{17}$ where Ts-CD separates as a water insoluble precipitate which is to be dissolved in DMF before grafting on CS. While in the method reported by Gonil et al., ${ }^{13}$ the solubility of CD-g-CS was improved by quaternization but it also increased the reaction steps.

The reaction pathway for the preparation of CS-g-HP $\beta C D$ is given in following scheme 1 .

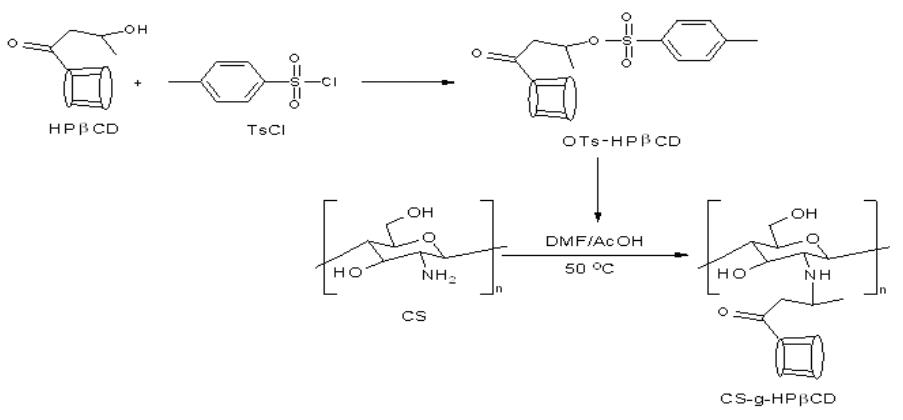

Figure 1: Characterization of chitosan-g-CS-g-HPßCD copolymer.

\section{Characterization of CS- $g-H P \beta C D$}

\section{Fourier transform infrared spectra (FT-IR)}

The FTIR spectra of CS, HP $\beta C D$, physical mixture of CS with HP $\beta C D$, CS-g-HP $\beta C D$ copolymer with varying ratios of CS to $\operatorname{HP} \beta C D$ (1:1, 1:2, 1:3 and 1:4), EFV and physical mixture of CS-g-HP $\beta C D$ with EFV are depicted Figure 1A. The FTIR spectrum of pure HP $\beta C D$ exhibited a broad band in between 3600 to $3100 \mathrm{~cm}^{-1}$ due to $\mathrm{O}-\mathrm{H}$ stretching and prominent peaks at 2929, 1645 and $1032 \mathrm{~cm}^{-1}$ corresponds to $\mathrm{C}-\mathrm{H}$, $\mathrm{H}-\mathrm{O}-\mathrm{H}$ bending and $\mathrm{C}-\mathrm{O}-\mathrm{C}$ respectively. The FTIR spectrum of CS had 
a broad band in between 3600 to $3000 \mathrm{~cm}^{-1}$ due to $\mathrm{O}-\mathrm{H}$ and $\mathrm{NH}_{2}$ groups whereas the absorption band at 1650 and $1379 \mathrm{~cm}^{-1}$ corresponds to the $\mathrm{C}=\mathrm{O}$ and $\mathrm{C}-\mathrm{O}$ stretching of amide group and absorption band at 1606 due to $\mathrm{NH}_{2}$ bending. CS showed absorption band at 1155, 1074 and 1029 $\mathrm{cm}^{-1}$ due to the symmetric stretching of the C-O-C and involved skeletal vibration of the $\mathrm{C}-\mathrm{O}$ stretching. In the FTIR spectrum of physical mixture of CS and HP $\beta C D$ all the major absorption peaks CS and $\mathrm{HP} \beta \mathrm{CD}$ were intact suggesting no interaction of polymers.

The FTIR spectra of copolymer prepared from CS:HP $\beta C D$ in the ratios of 1:1 and 1:2 retained all the prominent bands of both the polymers suggesting failure of graft formation between the polymers while the FTIR spectra of copolymer prepared from CS: HP $\beta$ CD in the ratio 1:3 displayed new bands which were comparatively more prominent in the copolymer formed from CS: HP $\beta C D$ in the 1:4 ratio. There was disappearance of some of the main peaks of both the polymers along with major changes in the finger print region.

In the FTIR spectrum of EFV sharp peak at $3317 \mathrm{~cm}^{-1}$ confirmed-NH stretching vibration which was supported by the evidence of $\mathrm{N}-\mathrm{H}$ deformation at $1496 \mathrm{~cm}^{1-}$. The absorption band at $1747 \mathrm{~cm}^{-1}$ corresponds to $\mathrm{C}=\mathrm{O}$ stretching vibration where as the absorption band at $2250 \mathrm{~cm}^{-1}$ was due to $-\mathrm{C} \equiv \mathrm{C}$-. The spectrum showed the absorption band at 3093 and $1600 \mathrm{~cm}^{-1}$ corresponding to the $\mathrm{C}-\mathrm{H}$ stretching and $\mathrm{C}$--- $\mathrm{C}$ stretching of the aromatic ring respectively. Absorption bands 690 and $652 \mathrm{~cm}^{-1}$ corresponds to $-\mathrm{CF}$ stretch while bands at 1097 and $1074 \mathrm{~cm}^{-1}$ corresponds to C-O-C stretch vibration. Absorption band at 1242 and $1166 \mathrm{~cm}^{-1}$ confirms $\mathrm{CN}$ and $\mathrm{CO}$ groups respectively. All bands of EFV were found intact at their original frequency in the spectrum of physical mixture with copolymer suggesting no interaction of drug with co-polymer.

\section{Nuclear magnetic resonance spectroscopy (NMR)}

Figure $1 \mathrm{~B}$ shows the ${ }^{1} \mathrm{H}$ NMR spectra of $\mathrm{CS}$ and its copolymer with $\mathrm{HP} \beta C D$ in the different ratios of CS: $\operatorname{HP} \beta C D(1: 1,1: 2,1: 3$ and 1:4) in $\mathrm{D}_{2} \mathrm{O}$ at $400 \mathrm{MHz}$. The ${ }^{1} \mathrm{H}$ NMR spectrum of CS exhibited the singlet proton at $\delta 4.73 \mathrm{ppm}$ for $-\mathrm{OH}$. The singlet protons at $\delta 4.68$ and $\delta 4.48$ ppm were assigned to $\mathrm{H}_{1}$ and $\mathrm{H}_{4}$ respectively where as the doublet at $\delta 3.87$ and $\delta 3.71 \mathrm{ppm}$ was assigned to $\mathrm{H}_{2}$ and $\mathrm{H}_{3}$ while the singlet at $\delta 3.60$ ppm was indicated for $\mathrm{H}_{5}$ in CS The singlet proton for $\mathrm{H}_{6}$ was observed at $\delta 2.86 \mathrm{ppm}$ and singlet proton at $\delta 1.97 \mathrm{ppm}$ was assigned to $-\mathrm{NH}_{2}$

The ${ }^{1} \mathrm{H}$ NMR spectrum of copolymer prepared from CS and HP $\beta C D$ in the ratio of 1:1 displayed the multiplet proton signals at $\delta 3.93-\delta 3.41$ ppm due to $\mathrm{H}_{2}, \mathrm{H}_{3}$ and $\mathrm{H}_{5}$. The appearance of singlet proton at $\delta 3.26 \mathrm{ppm}$ was due to $\mathrm{H}_{6}$ in the copolymer The side chain protons of $\mathrm{HP} \beta C D$ appeared as a singlet signals at $\delta 2.93$ and $2.77 \mathrm{ppm}$ due to $\mathrm{H}_{7} \mathrm{H}_{8}$ respectively. Doublet in the spectrum of copolymer at $\delta 1.07 \mathrm{ppm}$ was due to $\mathrm{H}_{9}$ and singlet signal of proton at $\delta 2.32 \mathrm{ppm}$ was assigned to $\mathrm{H}_{11}$ The ${ }^{1} \mathrm{H}$ NMR spectrum of copolymer exhibited new peaks, double of doublet proton signals, at $\delta 7.6-7.2 \mathrm{ppm}$ due to the aromatic protons of tosyl group. Doublet at higher side was assigned to ortho and lower side to meta protons. The singlet signals for $\mathrm{H}_{1}$ and $\mathrm{H}_{4}$ in copolymer were assigned at $\delta 4.9$ and $\delta 4.7 \mathrm{ppm}$. The singlet proton signal at $\delta 5.1 \mathrm{ppm}$ was an indication of presence of $-\mathrm{OH}$. There was no definite evidence for formation of copolymer between $C S$ and $\mathrm{HP} \beta \mathrm{CD}$ prepared with 1:1 ratio of CS: HP $\beta C D$. The ${ }^{1} \mathrm{H}$ NMR spectrum of CS and HP $\beta C D$ copolymer in the ratio of 1:2, 1:3 and 1:4 exhibited the similar pattern of the signals with varying intensities. The spectrum did not reveal the evidence for the formation of copolymer even with 1:2 ratio however the NMR of copolymers of CS with HP $\beta C D$ in the 1:3 and 1:4 ratios of CS: HP $\beta C D$ displayed an additional strong band at $\delta 4.7 \mathrm{ppm}$ revealing the formation of copolymer in between them. The ${ }^{1} \mathrm{H}$ NMR spectrum of copolymer in the ratio of $1: 4$ showed the involvement of $-\mathrm{OH}$ group of $\mathrm{HP} \beta \mathrm{CD}$ with $\mathrm{NH}_{2}$ group of CS in copolymer formation.

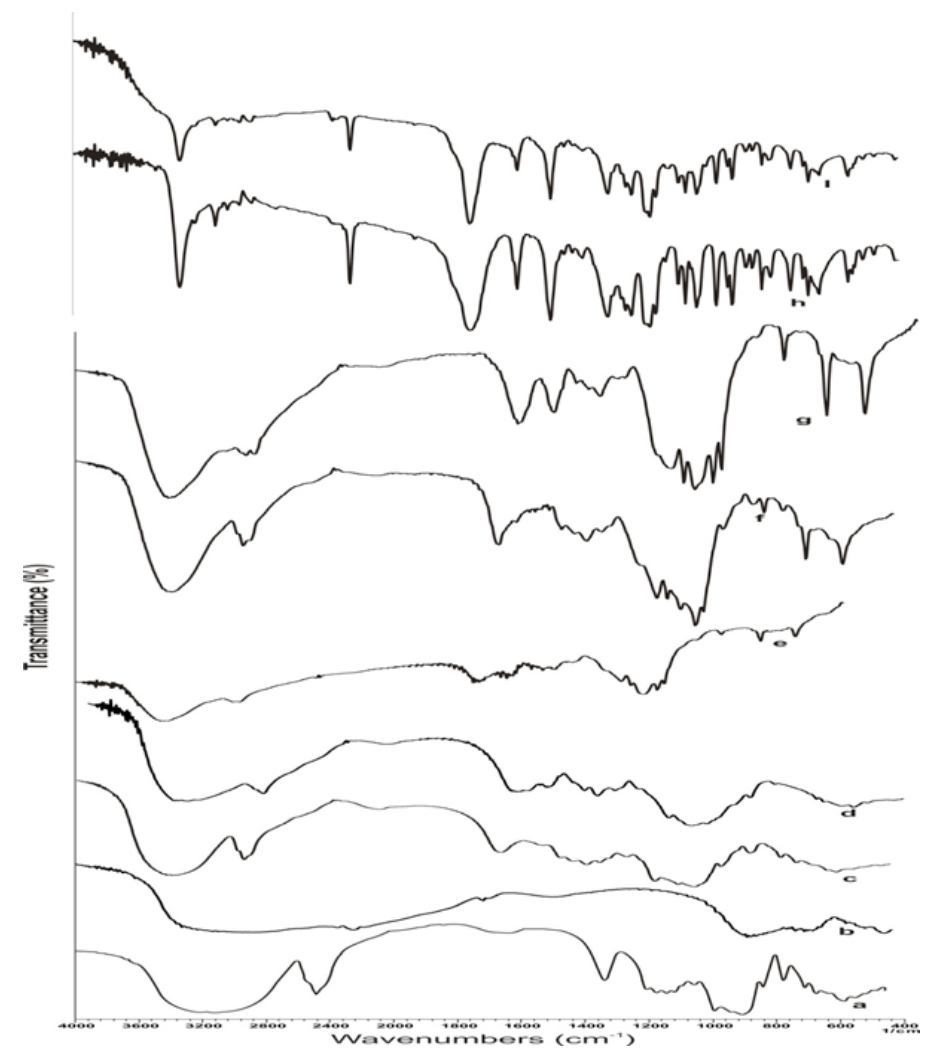

Figure 1A: FTIR spectra of (a) chitosan, (b) HP $\beta C D$, (c) physical mixture of CS and HP $\beta C D$, (d) CS-g-HP $\beta C D$ [1:1], (e) CS-g-HP $\beta C D$ [1:2], (f) CS-g-HP $\beta C D$ [1:3], (g) CS-g-HPßCD [1:4], (h) EFV and (i) physical mixture of EFV and CS-gHPBCD.

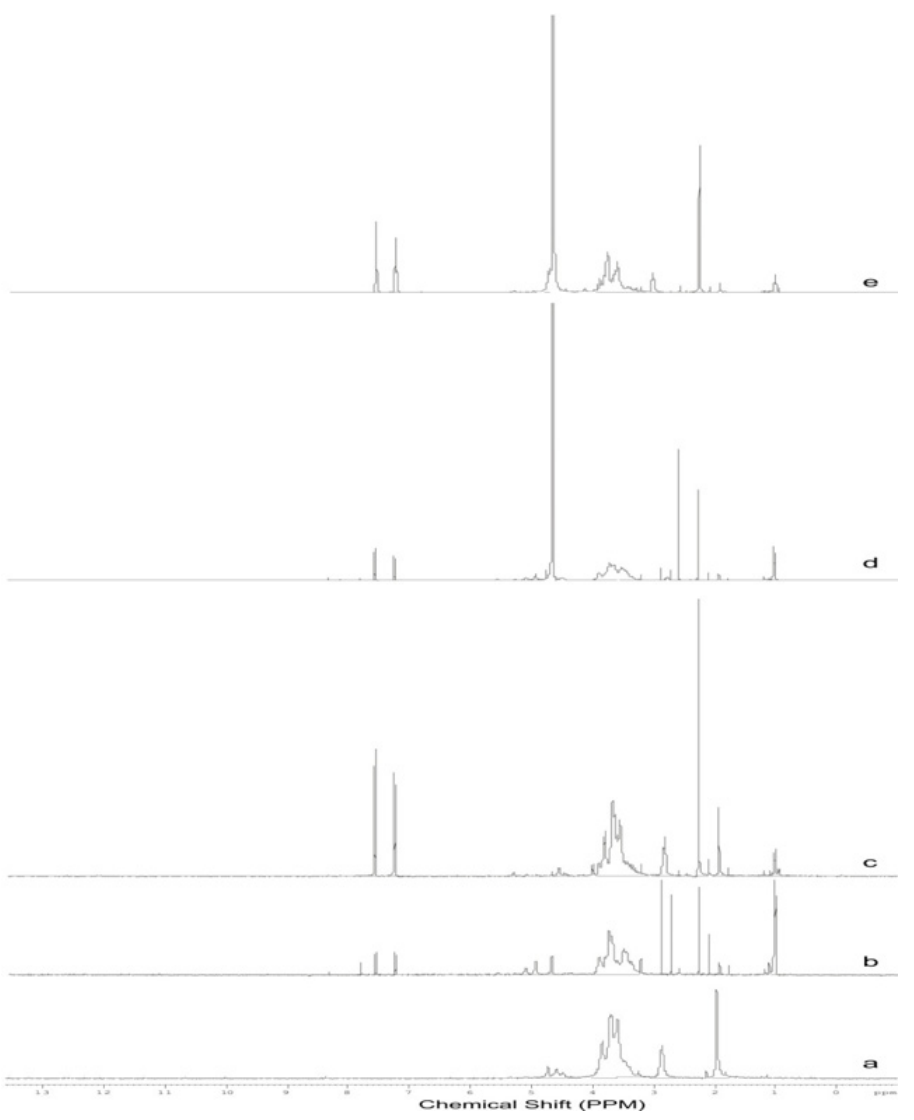

Figure 1B: 'H NMR spectra of (a) chitosan, (b) CS-g-HPßCD [1:1], (c) CS-gHP $\beta C D$ [1:2], (d) CS-g-HPßCD [1:3], (e) CS-g-HPßCD [1:4]. 


\section{Differential scanning calorimetry (DSC)}

DSC thermograms of CS, HP $\beta C D$, physical mixture of CS and HP $\beta C D$ (1:1), CS-g-HP $\beta C D$ copolymer, EFV and physical mixture of CS-gHP $\beta C D$ with EFV (1:1) are shown in Figure 1C. CS exhibited a broad endothermic peak at $258.07^{\circ} \mathrm{C}$ and exothermic peak above $310^{\circ} \mathrm{C}$ due to melting followed by decomposition of CS backbone. DSC thermogram of $\mathrm{HP} \beta \mathrm{CD}$ showed the initial loss of water upto $80^{\circ} \mathrm{C}$ followed by sharp endothermic peak at $109.71^{\circ} \mathrm{C}$ due to melting of $\mathrm{HP} \beta \mathrm{CD}$. In the physical mixture of CS and HP $\beta C D$ endothermic peaks of both CS and HP $\beta C D$ were retained at 310 and $109^{\circ} \mathrm{C}$ respectively which reflect compatibility between polymers. Endothermic peak of CS in CS-g-HP $\beta C D$ thermogram was found to shift to lower temperature $\left(231.46^{\circ} \mathrm{C}\right)$ as compared to pure CS. The shift in thermograms in copolymer was attributed to decrease in thermal stability as a consequence of decrease in crystalline nature. The shift in endotherms and exotherms of the copolymer to lower temperatures reveals early melting and decomposition of the copolymer. Substitution of HP $\beta C D$ into the CS backbone had reduced the strength of the backbone.

EFV thermogram showed a sharp melting endothermic peak at $139.16^{\circ} \mathrm{C}$ and exothermic peak attributed to decomposition at $265^{\circ} \mathrm{C}$. The compatibility of EFV with CS-g-HP $\beta$ CD copolymer was confirmed in physical mixture as there was no change in thermal behavior of EFV.

\section{Molecular weight determination}

The weight-average molecular weight $(\mathrm{Mw})$ was determined from Debye plot from the intercept at zero concentration shown in Figure 1D. The molecular weight of CS-g-HP $\beta C D$ was found to be $747 \pm 25 \mathrm{KDa}$ which was greater than molecular weight of CS ( $435 \mathrm{KDa})$. Increased molecular weight supports confirmation of grafting of HP $\beta C D$ on CS backbone.

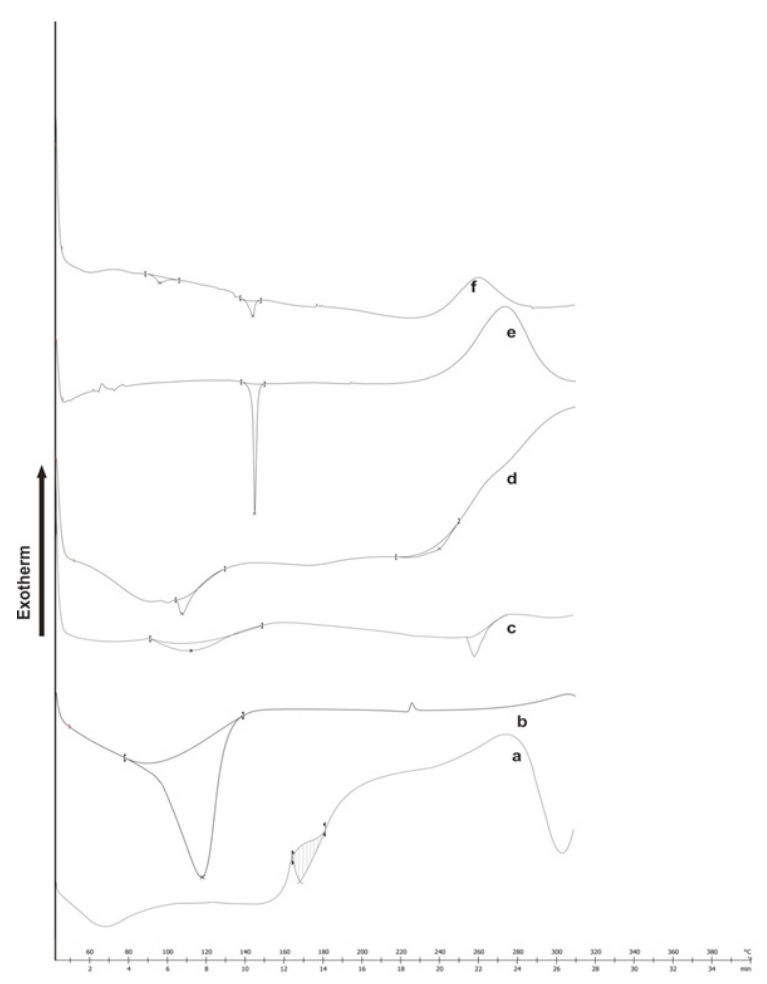

Figure 1C: DSC thermograms of (a) chitosan, (b) HP $\beta C D$, (c) physical mixture of CS and HP $\beta C D$, (d) CS-g-HPßCD copolymer, (e) EFV, (f) physical mixture of CS-g-HPßCD and Efavirenz .

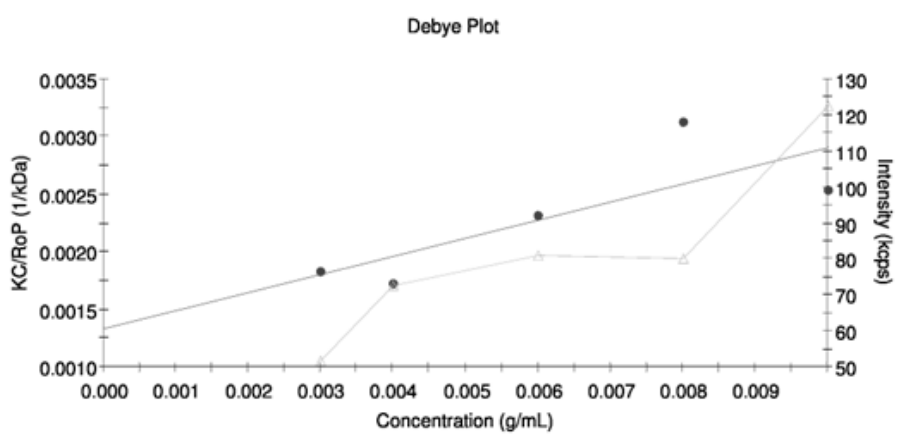

Figure 1D: Debey plot for molecular weight determination.

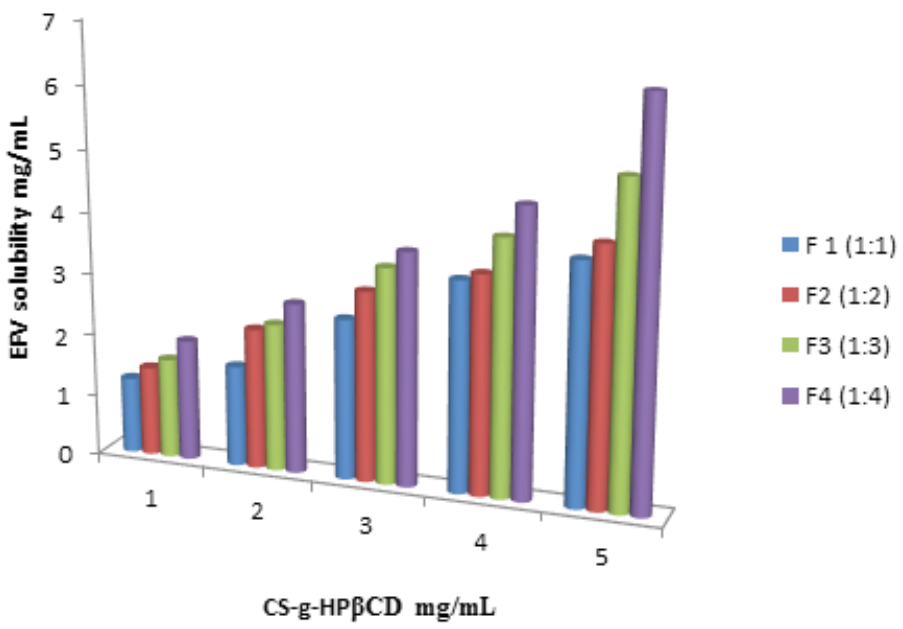

Figure 2: Solubility determination of EFV in CS-g-HP $\beta C D$. Data represents the mean $\pm S D, n=3$.

\section{Solubility determination}

Phase solubility curve was found to be $A_{L}$ type (Figure 2) as linear increase in drug concentration was observed as a function of grafted polymer. The slopes of the linear $\left(r^{2}=0.999\right)$ regions are all less than one, suggesting the formation of 1:1 drug/CD complex.

Equilibrium solubility of EFV in distilled water was found to be 0.0168 $\mathrm{mg} / \mathrm{mL}$. Solubility of EFV with grafted copolymer having 1:4 ratio of CS and HP $\beta C D$ was found to increase solubility of EFV 380 times than that of the free drug. This increase in solubility is higher than the techniques reported earlier such as nanosuspension, ${ }^{20}$ solid ternary system containing EFV, M $\beta C D$ and PVP K30, ${ }^{21}$ dendrimerization, ${ }^{22}$ composite hydrogel containing HEC-PAA ${ }^{23}$ and nanocrystalization. ${ }^{24}$

It was observed that with the increase in ratio of $\mathrm{HP} \beta C D$ in graft copolymer $(1: 1,1: 2,1: 3,1: 4)$ solubility of EFV was also increased. This might be attributed to combined effect of increased substitution of HP $\beta$ CD on CS. Also, copolymer offers more cup like structure through conjugation of $\mathrm{HP} \beta \mathrm{CD}$ with CS. This improved solubility may be due to the formation of inclusion complex between the hydrophobic cavities of CS-g-HP $\beta C D$ and EFV. This finding is corroborated by the DSC thermogram. Increase in the solubility of EFV may be due to the formation of hydrogen bond between $\mathrm{N}-\mathrm{H}$ and 'O' atoms of drug with -OH group of polymers.

\section{CONCLUSION}

Novel water soluble CS-g-HP $\beta$ CD grafted copolymer was successfully synthesized by tosylation using simple one-pot synthesis method. The solubility issues of EFV have limited its use in the treatment of AIDS. Grafted copolymer is an excellent strategy to conquer the solubility 
issues of hydrophobic drugs like EFV owing to solubility enhancement capability and mucoadhesivity. Authors are optimistic that the novel CS-g-HP $\beta C D$ will offer great opportunity as a carrier system with widespread application in developing novel drug delivery system for application across the transmucosal systems like nasal, ocular, vaginal and rectal.

\section{ACKNOWLEDGEMENT}

The authors acknowledge the Department of Science and Technology (DST), Government of India for funding the project under the program Women Scientist Scheme A (WOS-A) (SR/WOS-A/LS-528/2013).

\section{CONFLICT OF INTEREST}

No conflict of interest are declared.

\section{ABBREVIATION USED}

CS: Chitosan; CD: Cyclodextrin; QCD-g-CS: Quternized CD-g-CS; HP?CD: Hydroxypropyl-?-cyclodextrin; EFV: Efavirenz; NNRTI: Non nucleoside reverse transcriptase inhibitor; CS-g- HP?CD: Chitosangrafted-Hydroxypropyl-?-cyclodextrin; TS- HP?CD: Tosylated-HP?CD; FTIR: Fourier transform infrared spectra; NMR: Nuclear magnetic resonance spectroscopy ; DSC: Differential scanning calorimetry; SLS: Static light scattering; Ts-CD: Tosylated-Cyclodextrin.

\section{REFERENCES}

1. Wang JJ, Zeng ZW, Xiao RZ, Xie T, Zhou GL, Zhan X et al. Recent advances of chitosan nanoparticles as drug carriers. Int J Nanomedicine. 2011;6(9):765-4.

2. Prabaharan M, Mano JF. Chitosan derivatives bearing cyclodextrin cavities as novel adsorbent matrices. Carbohydr. Polym. 2006;63(2):153-66

3. Jayakumara R, Prabaharan M, Reis RL, Mano JF. Graft copolymerized chitosanpresent status and applications. Carbohydr. Polym 2005;62(2):142-58.

4. Xie WM, Xu PX, Wang W, Lu Q. Antioxidant activity of water-soluble chitosan derivatives. Bioorg Med Chem Letters. 2001;11(13):699.

5. Xie W, Xu PX, Liu Q, Xue J. Graft-copolymerization of methylacrylic acid onto hydroxypropyl chitosan. Polymer Bulletin. 2002;49(1):47-54.

6. Yang ZK, Yuan Y. Studies on the synthesis and properties of hydroxyl azacrown ether-grafted chitosan. J Appl Polym Sci. 2001;82(8):1838-43.

7. Jung BO, Kim CH, Choi KS, Lee YM, Kim JJ. Preparation of amphiphilic chitosan and their antimicrobial activities. J Appl Polym Sci. 1999;72(13):1713-9.

8. Loftsson T, Jarho P, Másson M, Järvinen T. Cyclodextrins in drug delivery. Expert Opin Drug Deliv. 2005;2:335-51.
9. Prabaharan M, Mano JF. Hydroxypropyl chitosan bearing $\beta$-cyclodextrin cavities: Synthesis and slow release of its inclusion complex with a model hydrophobic drug. Macro Mol Biosci. 2005;5(10):965.

10. Chen S, Wang Y. Study on $\beta$-cyclodextrin grafting with chitosan and slow release of its inclusion complex with radioactive iodine. J Appl Polym Sci. 2001;82(10):2414-21.

11. Lu L, Shao $X$, Jiao $Y$, Zhou $C$. Synthesis of chitosan graft- $\beta$-cyclodextrin for improving the loading and release of doxorubicin in the nanoparticleS. J Appl Polym Sci. 2014;41034:1-7.

12. Luzardo-Alvarez A, Antelo-Queijo A, Soto VH, Blanco-Mendez J. Preparation and characterization of $\beta$-cyclodextrin-linked chitosan microparticles. J Appl Polym Sci. 2012;123(6):3595-04.

13. Gonil P, Sajomsang W, Ruktanonchai UR, Pimpha N, Sramala I, Nuchuchua O et al. Novel quaternized chitosan containing $\beta$-cyclodextrin moiety: Synthesis, characterization and antimicrobial activity. Carbohydr Polym. 2011;83(2):905-13.

14. Sajomsang W, Nuchuchua O, Gonil P, Saesoo S, Sramala I, Soottitantawat A et al. Water-soluble $\beta$-cyclodextrin grafted with chitosan and its inclusion complex as a mucoadhesive eugenol carrier. Carbohydr. Polym 2012; doi:10.1016/j.carbpol.03.060.

15. Chiappetta DA, Hocht C, Opezzo JA, Sosnik A. Intranasal administration of antiretroviral-loaded micelles for anatomical targeting to the brain in HIV. Nanomedicine 2012; doi: 10.2217/NNM.12.104@2012 Future Medicine Ltd.

16. Marzolini C, Telent A, Decostered L, Biollaz J, Buclin T. Efavirenz plasma levels can predict treatment failure and central nervous system side effects in HIV1-infected patients. AIDS. 2001;15(1):1193-94.

17. Brady B, Lynam N, O'Sullivan T, Ahern C, Darey R. 6A-O-p-toluenesulfonyl$\beta$-cyclodextrin: ( $\beta$-Cyclodextrin, 6A-(4- methylbenzenesulfonate). Organic Synthesis. 2000;77:220-4.

18. Higuchi T, Connors KA. Phase solubility techniques. Adva Anal Chem Instru. 1965;4:212-17.

19. Patel AR, Vavia PR. Preparation and evaluation of taste masked famotidine formulation using drug/ $\beta$ cyclodextrin approach. AAPS Pharm Sci Tech. 2008; 9(2):544-50.

20. Taneja S, Shilpi S, Khatri K. Formulation and optimization of Efavirenz nanosuspensions using the precipitation-ultrasonication technique for solubility enhancement. Artificial Cells, Nanomedicine, and Biotechnology. 2015; doi: 10.3109/21691401.2015.1008505.

21. Vieira ACC, Fontes DAF, Chaves LL et al. Multicomponent systems with cyclodextrins and hydrophilic polymers for the delivery of Efavirenz. Carbohydr Polym. 2015;130:133-40.

22. Vijayarajkumar $P$, Choudhary RK, Narne R. Efavirenz loaded novel citric acid dendritic architecture for increased solubility and sustained delivery. J Pharm Drug Deliv Res. 2012;1:1.

23. Mabrouk M, Chejara DR, Mulla JAS, Badhe RV, Choonara YE, Kumar P, et al Design of a novel crosslinked HEC-PAA porous hydrogel composite for dissolution rate and solubility enhancement of efavirenz. Int J Pharm. 2015;490(1):429-37.

24. Karri V, Butreddy A, Dudhipala N. Fabrication of efavirenz freeze dried nanocrystals: Formulation, physicochemical characterization, in-vitro and ex vivo evaluation. Adv Sci Engg Med. 2015;7(5):385-92.

Article History: Submission Date: 04-11-16; Received Date: 26-12-16; Acceptance Date: 02-01-17.

Cite this article: Belgamwar A, Khan S, Rathi L. Synthesis of Chitosan-Graft- HPBCD Copolymer by Novel One Pot Technique and its application for Solubility Enhancement of Efavirenz. J Young Pharm. 2017:9(2):172-6. 